\title{
Entre a cidade alta e a fazenda de Pau d'Arco: uma leitura de Brandão entre o mar e o amor
}

\author{
Marcos Vinícius Teixeira* \\ Universidade Estadual do Mato Grosso do Sul \\ Dourados, Brasil \\ Recebido em: 14/04/2019 \\ Aceito em: 01/o8/2019
}

\begin{abstract}
Resumo: Em 1941, Graciliano Ramos, Jorge Amado, José Lins do Rego, Rachel de Queiroz e Aníbal Machado iniciaram, de forma coletiva, a escrita do romance Brandão entre o mar e o amor, que foi publicado nas páginas da revista Diretrizes de agosto daquele ano até fevereiro de 1942, resultando em uma obra instigante, que vem sendo reeditada, mas que ainda hoje tem despertado pouco interesse do público e da crítica. Os estudos dedicados a esse romance são raros a despeito da reputação de seus autores. A proposta deste artigo é realizar uma leitura desta obra, avaliando-se aspectos da construção ficcional.
\end{abstract}

Palavras-chave: Brandão entre o mar e o amor. Romance coletivo. Segunda guerra mundial. $\mathrm{O}$ campo e a cidade.

Abstract: In 1941, Graciliano Ramos, Jorge Amado, José Lins do Rego, Rachel de Queiroz and Aníbal Machado began the collective writing of the novel Brandão between the sea and love, which was published on the pages of Diretrizes magazine from August of that year until February 1942, resulting in an instigating work that has been reedited, but so far still raises little interest from the public and critics. Studies devoted to this novel are rare despite the reputation of that authors. This article aims to present an interpretation of that work, assessing aspects of the fictional construction.

Keywords: Brandão between the sea and love. Collective novel. Second world war. The country and the city.

Résumé: En 1941, Graciliano Ramos, Jorge Amado, José Lins do Rego, Rachel de Queiroz et Aníbal Machado ont commencé à écrire, de manière collective, le roman Brandão entre la mer et l'amour, lequel a été publié dans les pages du magazine Diretrizes - d'août 1941 jusqu'en février 1942. Le résultat c'est une oeuvre passionnante qui, malgré ses rééditions, démeure peu interessante auprès du public et de la critique littéraire. Les études vouées à ce roman sont rares en dépit de la renomée de ses auteurs. Cet article se propose alors d'en faire sa lecture tout en mettant en évidence des aspects de sa construction en tant qu'oeuvre fictionnelle.

Mots-clés: Brandão entre la mer et l'amour. Roman collectif. Seconde guerre mondiale. La campagne et la ville. 


\section{Introdução}

Há na literatura brasileira algumas obras que despertam o interesse por reunir nomes importantes na escrita de uma ficção de forma coletiva. É o caso de obras como $O$ capote do guarda, O mistério dos $M M M$ e Brandão entre o mar e o amor. A última, objeto de nosso estudo aqui, reuniu os autores Graciliano Ramos, Jorge Amado, José Lins do Rego, Rachel de Queiroz e Aníbal Machado e foi publicada pela primeira vez entre 28 de agosto de 1941 e 26 de fevereiro de 1942 na revista Diretrizes. Posteriormente, foi reunida em livro em julho de 1942, quando o mundo passava pela segunda grande guerra que teria pouco depois, naquele mesmo ano, a conhecida participação brasileira. A proposta deste artigo é realizar uma leitura do romance Brandão entre o mar e o amor tendo em vista duas perspectivas, a da parte e a do todo, avaliando-se aspectos da construção ficcional. Observa-se que há um mérito na realização das partes, que está relacionado à singularidade e à idiossincrasia de cada escritor, mas que vista em sua amplitude, em conjunto, a obra apresenta certas complicações que afetam um pouco a sua constituição.

Os escritores, oriundos de cinco estados diferentes, parecem unidos não só pela época em que vivem e, claro pela literatura que fazem, mas também e em alguma medida pela vida no Rio de Janeiro para onde foram em épocas distintas, cumprindo um curso comum a diversos escritores modernistas do período. Aníbal Machado se muda definitivamente para a capital do país em 1923. Jorge Amado seguirá para o Rio em 1930, mas viverá em outras cidades durante a década e com a instauração do Estado Novo, o escritor baiano vive no exterior entre os anos de 1941 e 1942, período que possivelmente contempla a redação de Brandão entre o mar e o amor. José Lins do Rego chegará em 1935. Já o percurso de Graciliano Ramos é diferente, nesse sentido, pois é preso e levado para o Rio de Janeiro em 1936, ganhando a liberdade no ano seguinte. Raquel de Queiroz se muda para a cidade um pouco depois, em 1939.

A primeira edição do romance coletivo não traz nenhuma informação sobre o projeto do livro. As edições posteriores a que tive acesso também não trazem. Vamos encontrar na própria revista Diretrizes informações sobre o 
projeto do livro. No dia 3 de março de 1941, anuncia-se que a obra será publicada como folhetim e os autores que a escreverão:

\begin{abstract}
Com efeito, Aníbal Machado, Graciliano Ramos, Jorge Amado, José Lins do Rego e Raquel de Queiroz, atendendo ao nosso convite, começarão a publicar, dentro em breve, em Diretrizes, uma novela de documentação do meio e da época em que vivemos.

Sem plano pré-estabelecido, sem que Diretrizes lhes tenha sugerido sequer o título da obra, incumbindo-se cada um desses autores, com a mais irrestrita liberdade, da parte que lhe couber no romance, pode-se afirmar que esse empreendimento constituirá, sem dúvida, um dos grandes êxitos literários do ano de 41. (DIRETRIZES, 1941, p. 2.)
\end{abstract}

Anunciado em março, o romance de folhetim só começa a ser publicado em agosto. Divulgado como uma novela, é preciso considerar que pelos critérios adotados, isto é, o da liberdade total para a escrita dos capítulos, os editores não tinham como mesurar nem a complexidade da obra nem mesmo o seu tamanho. Ainda acerca da notícia da obra, afirma-se que ela será escrita por "cinco dos nossos maiores romancistas modernos", apesar de Aníbal Machado ainda não ter publicado a sua primeira obra neste momento, mas já ser conhecido como contista, e que posteriormente a editora Martins publicará o livro em São Paulo. Noticia-se ainda que haverá um prêmio para os leitores que identificarem o nome dos respectivos autores dos diferentes capítulos do romance. Com isso, os capítulos aparecem na revista sem a identificação da autoria, que só será revelada somente no dia 30 de julho de 1942. Um detalhe importante no texto da revista é que se enfatiza que são autores modernistas que tratarão da atualidade, afirmando-se que será uma obra de "documentação do meio e da época em que vivemos". Jorge Amado no primeiro capítulo registra o tempo histórico da obra e depois Aníbal Machado desenvolverá este ponto. Os outros autores, no entanto, não darão a mesma importância ao tempo da escrita do livro e o espaço rural na ficção promoverá um certo alheamento em algumas partes a este critério inicial.

Na biografia $O$ velho Graça, Dênis de Moraes nos informa que a ideia da construção da obra teria sido de Aníbal Machado e que Graciliano Ramos foi o último escritor convidado para a experiência coletiva:

[Graciliano Ramos] Participou também do romance Brandão entre o mar e o amor, escrito a dez mãos. A ideia, de Aníbal Machado, ganhara de pronto a adesão de Rachel de Queiroz, Jorge Amado, José Lins do 
Rego. Oito mãos - faltavam as duas de Graciliano, que não pensou duas vezes em juntar-se à brincadeira.

O processo de elaboração seria curiosíssimo: um autor preparava o capítulo e passava-o a outro, que tinha de dar sequência à trama. "O problema é que cada um fazia o seu capítulo encrencando mais a história para o companheiro seguinte resolver", recordaria Rachel. Quando chegou a vez dela - era a última -, o recurso foi matar todos os personagens, pois não havia mais nada a fazer. (MORAES, 2012, p, 192.)

É possível que Aníbal Machado tenha levado a ideia da obra coletiva para a revista Diretrizes. Vale lembrar que o escritor mineiro havia participado no início dos anos 1920 de uma novela coletiva, O capote do guarda, que foi publicada também em jornal na cidade de Belo Horizonte, mas que acabou caindo no esquecimento durante muito tempo por não ter sido publicada em livro. Nesta, a abordagem da capital mineira da época da escrita do livro é de suas características mais relevantes. Com relação à afirmação de Rachel de Queiroz é preciso notar uma ambiguidade na ideia de encrencar a história, pois, como veremos, isso se deveu à inexistência de um projeto para o enredo e não exatamente por uma certa malícia do escritor precedente. De fato, o capítulo de Aníbal Machado, que a precedeu, deixa-a em situação um pouco complicada para a redação do último capítulo, como mostraremos, mas não é possível afirmar o mesmo para os demais escritores.

A historiadora Ana Paula Palamartchuk afirma que os escritores se reuniram no início de 1941 para organizar a sequência da escrita. Vejamos:

Graciliano Ramos foi convidado por Aníbal Machado para escrever uma novela coletiva. Além de Machado e Graciliano, escreveriam no romance Rachel de Queiroz, José Lins do Rego e Jorge Amado. No início de 1941, reuniram-se e combinaram que o romance seria escrito sem um plano de redação ou um enredo preestabelecido. Cada um escreveria a sequência do anterior. Escolheram Jorge Amado para escrever o primeiro capítulo. (PALAMARTCHUK, 2011, p. 12)

É bastante significativo que cinco grandes escritores da literatura brasileira tenham se reunido e pensado juntos o projeto de uma obra literária, ainda que a liberdade de criação tenha prevalecido sobre a mesma. Tal liberdade proporcionará as duas questões levantadas aqui, ou seja, uma boa construção individual de cada parte da ficção, mas certa complicação ligada à ação, que é 
lenta e interiorizada, e, especialmente, ao rumo tomado pelo enredo, como se verá. Para tanto, comentaremos inicialmente as partes em separado, mas pontuando possíveis contradições entre elas, para, em seguida, avaliar a obra como um todo.

Jorge Amado escreve a primeira das cinco partes que compõem o romance Brandão entre o mar e o amor. Sob o título de "Mais que branca, mais que pálida", o escritor baiano cumpre o seu papel de introduzir as personagens atribuindolhes universos e alguma complexidade. O título de sua parte traz uma percepção acerca da personagem Lúcia, marcada justamente pela dificuldade de ser apreendida ou caracterizada. Quando, no capítulo VI, descobre-se um pouco mais sobre ela, na cena em que a ida a um médico é rememorada, tal como o fato de que é preciso ser feliz nos próximos meses de vida, somos logo desenganados e descobrimos que quem tem pouco tempo de vida é seu marido Pedro Brandão.

A história de Brandão nos é desenhada: filho de juiz, decepciona o pai ao largar o estudo do Direito e entrar para a vida de um circo. Depois, ao viajar com os artistas circenses de navio, muda de ideia e se torna marinheiro, correspondendo a uma antiga vontade. Numa de suas viagens, conhece Lúcia e a salvará durante um naufrágio. Juntos, escolhem viver em terra firme e vão viver na fazenda de Pau d'Arco, que herdara do pai, agora falecido. Na fazenda, convivem com Dona Elisabeth, mãe de Brandão, e Mário, que aceita passar uns dias com seu antigo amigo dos tempos da faculdade.

Brandão reencontrara Mário vivendo um casamento em crise. A esposa, Glória, queixa-se o tempo todo da situação financeira em que vivem, comparando sempre o marido ao próprio pai, também advogado. A narrativa a caracteriza como "brusca e autoritária, vaidosa e inquieta". No capítulo IV somos informados de que Mário está na fazenda do amigo há oito dias e acaba se interessando por Lúcia, a quem pergunta se é feliz.

Paralelamente ao círculo de Brandão, Jorge Amado insere outros personagens na narrativa. Aparecem Vicente e Joana, de classe social mais baixa que os demais e em constantes dificuldades. Vicente se acidentou em um desastre de bonde e ficou de cama, tornando a vida ainda mais pesada para Joana, que, além dos trabalhos feitos em casa, é empregada de dona Glória em um 
atelier de costura. Há várias digressões na narrativa de Jorge Amado, que nos explica o passado de vários personagens. Se, por um lado o procedimento ajuda a fornecer diversos elementos para o próximo escritor continuar a história, por outro acaba tornando um pouco intricada a narrativa, pois elas permeiam uma história com certas inversões no enredo. Ainda assim, a organização é boa se tivermos em vista a forma como termina a sua parte.

José Lins do Rego dá sequência ao romance escrevendo a segunda parte "Mistério de Brandão (Glória)". Realiza nova digressão e trabalha o passado da personagem Glória. Os preconceitos da personagem não aparecem como na primeira parte do livro ou diminuem e a sua relação com o pai se altera ou se desnuda de forma significativa, revelando-se a rejeição para com ele. Atribui-lhe também certa veleidade que faz recusar vários noivos até se casar com Mário. Nesse sentido há interessante intertextualidade com a história de Branca de neve. A nova digressão, apesar de atrasar a ação, é importante para construir novo conflito na narrativa, no caso, o fato de dona Glória se apaixonar por Brandão e por ter encontrado cartas do marido a uma amante. Se as novas complicações são bem articuladas, há, no entanto, problemas que devem ser considerados. A situação do casal parece ser bastante diferente em relação ao que escrevera Jorge Amado. Possuem, por exemplo, vários criados e surpreende o fato de as crianças não aparecerem para dividir a situação da mãe, agora sozinha o tempo todo. Na parte de Jorge Amado ficara nítido que dona Glória possuía uma menina e um menino. O escritor baiano havia inserido a preocupação com a guerra, o que delimita temporalmente o enredo próximo ao ano de publicação do romance em 1942. Já o escritor paraibano delimita o espaço, que agora sabemos ser a Bahia. Um bairro de Salvador, Amaralina, também é mencionado em sua parte.

José Lins do Rego termina a sua parte narrando a chegada de um telegrama à casa de dona Glória, em que se comunica que Mário está muito mal de saúde e que ela deveria ir até a fazenda ver o seu marido. A doença de Mário acaba provocando uma mudança de rumo muito forte no romance, pois seria natural que, restando pouco tempo de vida a Brandão e dada a figura desconhecida de Lúcia, a narrativa se concentrasse de forma tensionada numa corrida contra o tempo. Graciliano Ramos, que assina a terceira parte intitulada 
"Mário", nos descreve a situação deste personagem numa narrativa saborosa que nos lembra os devaneios de Paulo Honório em S. Bernardo. Aqui, no entanto, marcada pelo drama da doença. Mário, moribundo, vai recuperando alguns episódios de sua vida. Esclarece-se que a possível amante desapareceu. A esposa aparece, mas a sua presença se atribui significação diferente. Mário, entre a autoridade do fim da vida e a insignificância de se sentir como um móvel na casa, escreve um caderno no qual registra impressões sobre as pessoas que o cercam.

Ao redigir a quarta parte, "O mar triunfante", Aníbal Machado recupera em linhas gerais o enredo do romance e constrói um movimento interessante, reunindo os personagens em Pau d'Arco e depois esvaziando a fazenda. Por outro lado, durante a narrativa do escritor mineiro, opera-se um lento afastamento entre Brandão e Lúcia. D. Elisabeth, mãe daquele, embora sempre aparecendo pouco, acompanha tudo o que ocorre na fazenda e o cotidiano dos personagens. Por meio dela vemos dona Glória chegar de uma caminhada em momento em que Brandão também estivera fora de casa. $\mathrm{O}$ encontro entre eles é recuperado na narrativa pela perspectiva de Brandão:

\footnotetext{
Persistia-lhe ainda no braço o ardor das garras de Glorinha, e, nos ouvidos, o som rouco de seus apelos - apelos de uma mulher desvairada. Chegara a empurrá-la, com asco a princípio, depois com dó, quando a vira caída na relva. Ela segurava as rédeas do animal para que Brandão não partisse.

(AMADO, 1942, p. 91)
}

Preterida, dona Glória, agora chamada Glorinha, segue na fazenda com o objetivo de conquistar Brandão, não para amá-lo, mas para fazê-lo infeliz. A personagem ganha assim uma aura niilista, que já vinha sendo desenhada pelos outros autores: "Vontade de fazê-lo sofrer, de abraçar-se a ele para sempre, até liquidá-lo completamente. De destruir-se a si mesma” (AMADO, 1942, p. 102).

Solicitado pelo pai de dona Glória, um padre comparece à fazenda para aconselhá-la. Ocorre que, a pedido da própria personagem, também irá para lá o "pai de santo" ou "macumbeiro", como é chamado pela narrativa, chamado pai Leandro. Este vai com o propósito de abrir-lhe "o mundo tenebroso de Xangô", prometendo-lhe "a força do pecado, o triunfo no amor, a aventura". Assim, Glorinha passa algum tempo entre a vivência do que pode lhe dar prazer e o 
senso do dever. Ao tomarem conhecimento de que padre Xavier e pai Leandro estão na fazenda, e ainda de que um médico está para chegar, uma verdadeira multidão de necessitados comparece à fazenda em busca de alento.

De forma interessante, Aníbal Machado recupera a imagem das crianças que ficara esquecida nas narrativas anteriores. É uma das motivações que terá o pai dela para também viajar até a fazenda de Brandão e ir vê-la. Neste momento, porém, a fazenda começa a se esvaziar com a partida de pai Leandro. Ainda aparece em Pau d'Arco, nesse meio tempo, um curioso médico chamado Dr. Jax, que trata as pessoas de forma mística e se interessa mais pelos papéis que Mário escreve do que pelo exame que fez. O místico despertará o interesse de Lúcia, que se declara a ele e ao mesmo tempo demonstra o crescente desinteresse por Brandão.

As folhas que se soltam curiosamente do caderno de Mário e vão sendo levadas, talvez pelo vento, para todos os lugares da Bahia ajudam a divulgar os acontecimentos íntimos dos personagens. A imagem das folhas que se soltam e são encontradas em lugares diferentes assim como a cena em que Brandão tem um acesso de ciúmes ao ver que Lúcia lhe esconde um papel onde escrevia alguma coisa dialogam de forma interessante com o já mencionado $S$. Bernardo, de Graciliano Ramos. Comparemos os fragmentos, lendo primeiro a cena em que Paulo Honório encontra uma folha de uma suposta carta de Madalena e é invadido pelo ciúme:

No dia seguinte encontrei Madalena escrevendo. Avizinhei-me nas pontas dos pés e li o endereço de Azevedo Gondim.

- Faz favor de mostrar isso?

Madalena agarrou uma folha que ainda não havia sido dobrada.

- Não tem que ver. Só interessa a mim.

- Perfeitamente. Mas é bom mostrar. Faz favor?

$[\ldots]$

- Deixa ver a carta, galinha.

Madalena desprendeu-se e entrou a correr pelo quarto, gritando:

- Canalha!

(RAMOS, 2006, p. 185)

Veja-se agora a cena em que Brandão desconfia de Lúcia e tem ímpetos de agressividade num diapasão bem diferente ao que a narrativa vinha lhe pintando, mas que nos faz lembrar da obra de Graciliano Ramos. 
Ao entrar no quarto, Brandão notou que Lúcia escondia o papel em que escrevera qualquer coisa: - "Se deixaste algum amor pelo Japão pode dizer. Nesse caso, desmancharemos a nossa vida comum”.

Ela sorriu com perfídia. Brandão mal conteve o impulso de espancá-la. De espancá-la com o mesmo ardor com que a abraçava nos primeiros dias.

(AMADO, 1942, p. 101)

Dr. Jax segue para Salvador, de onde pretende escrever falando do mal de Mário. Lúcia, após receber a visita de um estranho que lhe trouxera um embrulho, também parte para Salvador com o endereço do médico na bolsa. Quando retorna, não encontra mais o marido na fazenda. Saberemos depois que voltou para o mar, para a vida de marinheiro. Aos poucos, todos vão deixando a fazenda, onde D. Elisabeth fica só, aguardando notícias do filho.

Aníbal Machado aproveita o tempo histórico fornecido na primeira parte por Jorge Amado para desenvolver o motivo da fuga de Brandão para o mar, onde se une a outros marinheiros e pode lutar pelo país durante a Segunda Grande Guerra. À medida que o cotidiano da fazenda lhe sufoca, o personagem se refugia ouvindo o rádio, que lhe traz notícias do mundo. Interessante observar que a marca da guerra pode estar até no tratamento dado a Lúcia, que desde o início do romance levanta suspeitas de ter origem chinesa. Na parte do escritor mineiro, porém, ela tem suposta origem japonesa, como se vê no fragmento acima e como se cogita na carta que Brandão escreve para sua mãe dando notícias e dizendo que lhe falaram que Lúcia seria brasileira de São Paulo, mas filha de japoneses. Brandão atende aos apelos do rádio, volta para o mar e participa da guerra. Nesta mesma carta, afirma que se serviu do mar quando precisou em suas aventuras e que agora era o mar quem necessitava dele. Há de fato uma tomada de consciência em Brandão sobre a sua importância para o momento em que vive, sendo preferível, na visão do personagem, arriscar a sua vida no mar fazendo a guerra do que arriscar a sua felicidade em terra firme. Aníbal Machado abordou o tema da guerra em outros textos seus publicados no livro Cadernos de João e, no caso da participação brasileira na guerra, no conto “O piano”.

No artigo "Entre o mar e o amor... guerra e romance no Brasil contemporâneo", a historiadora Ana Paula Palamartchuk aborda o posicionamento político dos escritores em relação à época em que viveram, 
especialmente a partir de 1933, considerando as organizações políticas e os episódios que marcaram o período. Ela nos informa, por exemplo, que Jorge Amado e Aníbal Machado assinaram o manifesto de fundação da Liga de Defesa da Cultura, ligada à Aliança Nacional Libertadora, contra a qual há uma ofensiva do governo após a aprovação da lei de segurança nacional. Em outro manifesto publicado na revista Dom Casmurro, desta vez em defesa dos espanhóis republicanos, segundo Palamartchuk, dentre os escritores que subscrevem estão Jorge Amado, Graciliano Ramos, José Lins do Rego e Aníbal Machado. Ao abordar Brandão entre o mar e o amor a historiadora ressalta a parte de Aníbal como uma forte mudança de rumo na narrativa, que se desvia do tema amoroso e se envereda por um viés mais engajado.

Como mostramos, a narrativa de Aníbal acaba deixando Rachel de Queiroz, que a continuará, em situação difícil, pois distancia personagens importantes como Brandão e Lúcia, dando rumo incerto para ambos. Há uma diminuição ou resolução dos conflitos, o que acaba proporcionando a sensação de término do enredo. Rachel de Queiroz não aborda a atuação de Brandão na guerra. O personagem reaparece no cais da Bahia, onde reencontrará Lúcia, que o vinha esperando há dias. O retorno de Brandão parece marcado por uma pequena contradição, pois se afirma que ele deixou a bagagem no navio e depois somos informados de que foi mandado embora de seu navio porque um exame médico revelara um aneurisma em seu peito e poderia morrer a qualquer momento.

Lúcia e Brandão seguem para um café para conversar. Ela procura, de forma inútil, explicar-lhe que algumas coisas ditas a respeito dela eram mentira. Soubera de tudo pela mãe de Brandão, que voltou a viver na cidade. Raquel de Queiroz explora, assim, algumas lacunas que ficaram na narrativa anterior. Lúcia gostaria de retomar a vida de casada, mas Brandão está resoluto e a recusa de forma definitiva. A última carta de sua esposa é rasgada sem ser aberta. No caminho para a casa da mãe, a narrativa explora bem um trajeto pelas ruas de Salvador. Brandão pega um bonde, desce na estação terminal, como a sua vida, entra no elevador e vai dar na cidade alta. Lá pega um automóvel que o levará até o endereço da mãe. Chegando, encontrará dona Elisabeth de cama, bastante debilitada. Mário, por coincidência, mora perto e aparece numa noite para uma 
breve visita. Um mês depois, dona Elisabeth falece. Brandão despede a empregada e passa a viver sozinho. Logo em seguida, num dos passeios ao cais, vê um menino se acidentar ao pular para uma embarcação e afundar no mar. O antigo marinheiro tenta socorrê-lo e mergulha quatro vezes, fazendo grande esforço. Ao voltar com a vítima é retirado e passa mal. Falece em seguida, antes que uma ambulância consiga chegar.

A imagem criada por Rachel de Queiroz é bonita. O menino que salvou é chamado como "pretinho" e descrito como um pequeno pescador. O protagonista possui nome no aumentativo, Brandão, que dialoga, em oposição, com o pequeno. Carregando uma vara de pescar no ombro, o menino poderia ser tomado aqui como alguém que começa a sua vida em relação ao mar. Em contraposição, Brandão está finalizando a sua. Não há mais como salvar o menino que gosta do mar que vive dentro de si. A imagem do salvamento também nos remete à forma como acabou se aproximando de Lúcia, que é socorrida durante um naufrágio.

Ana Paula Palamartchuk (2011) faz uma leitura da última cena da obra relacionada aos acontecimentos históricos. Na obra, no momento de sua morte, Brandão deixa de enxergar as pessoas que o rodeiam e o seu olhar é "banhado de novo pela luz sangrenta do sol que se punha”. Em seguida, quando o médico constata a sua morte e lhe fecha os olhos, a narrativa informa que "apagava ao mesmo tempo um lampejo vermelho de sol que ainda brilhava nas pupilas vazias". Sobre a imagem relacionada aos olhos do personagem, a historiadora afirma: "É possível que a luz sangrenta do sol que Brandão viu no horizonte fosse a metáfora da Europa em guerra, que apagava um 'lampejo vermelho', a última esperança de um mundo melhor, que havia sido inspirado na URSS” (PALAMARTCHUK, 2011, p. 15).

Brandão entre o mar e o amor vem ganhando novas edições, ainda que de forma espaçada, mas não tem alcançado grande interesse do público e, em especial, da crítica literária. Vem sobrevivendo, aliás, como uma grande curiosidade literária, como um romance escrito por grandes nomes da literatura brasileira, o que de fato é. Se as partes forem observadas separadamente, não é difícil reconhecer a qualidade da escrita do romance. Quando analisadas em 
conjunto, no entanto, a obra não possui a mesma força que encontramos nas partes. A ação, na visão do todo, acaba marcada por um andamento lento. Há uma dimensão psicológica forte na obra, que na transição de universos literários acaba soando um pouco difusa quando observada no todo. Quando vista, no entanto, de forma pontual, é muitas vezes rica e bem realizada. Talvez a dimensão psicológica unida a um andamento lento da ação tenha trazido problemas para o conjunto da obra. Observe-se, por exemplo, que o romance começa com a cena em que Lúcia cuida da mão ferida de Mário na fazenda. Depois, ainda na parte de Jorge Amado, haverá uma digressão para se explicar a estadia do personagem na fazenda de Brandão. O leitor atravessa quatro partes da obra e Mário só sairá da fazenda ao final da quarta parte, escrita por Aníbal Machado, e que, como apontamos, encerra a seu modo várias questões do enredo. Assim, um personagem que passaria dias fora de casa, acaba ficando alguns meses e o que parecia ser apenas um episódio no romance cresce de forma injustificada. Como também pontuamos, a permanência de Mário na fazenda é fortalecida ao final da segunda parte, escrita por José Lins do Rego, que insere uma doença inesperada e urgente no personagem. Com isso, a ideia de luta contra o tempo, contra o pouco tempo de vida que restaria a Brandão, que poderia ser melhor aproveitada, é deixada de lado, pois a ênfase da obra muda para um doente mais urgente, Mário. Tudo isso, como apontamos no início deste artigo, talvez seja explicado pela liberdade do escritor traçada no projeto da obra.

Outro elemento interessante criado por Jorge Amado é o mistério de Lúcia, moça a priori encantadora, que deixa os homens enfeitiçados. Aos poucos, porém, vai se revelando muito superficial ao longo das partes, e, com isso, destoa de outra personagem, Glória, que acaba possuindo maior complexidade, ainda que repleta de negatividade. Lúcia ganha ares de impostora durante a quarta parte e se consolida como uma personagem desinteressante ao final do livro. A promessa de amor entre Lúcia e Brandão, traçada por Jorge Amado no início da obra, não se concretiza. Entre Lúcia e Mário nada pode haver, dada a perturbação do último. Entre Glória e Brandão nada tem início de fato e esta também não se acerta com seu marido. Assim, nenhuma promessa de amor se realiza na obra. Nem mesmo entre Brandão e o mar, que talvez seja o melhor casamento existente 
no romance, pois a doença vem lhe abreviar a segunda lua de mel com o mar. Se houve boa relação com o mar, não é desenvolvida na obra. Sempre é algo que aconteceu ou que não se narrou de fato, existindo mais como lembrança vaga do que como ação.

Após a publicação integral da obra, a revista Diretrizes publicou um texto no qual informa com cuidado quais são os autores de cada capítulo. Como dissemos no início deste artigo, Aníbal Machado foi listado como um grande autor, apesar de neste momento ainda não ter livro publicado. No texto em questão, os editores fazem uma curiosa ressalva nesse sentido:

\begin{abstract}
Ao continuá-lo, Aníbal Machado enfrentou uma situação perigosa. Nada menos de três grandes romancistas o tinham precedido. Embora ainda não seja autor de livro algum, o contista de "A Morte da Portaestandarte" é um dos mais conhecidos nos meios literários do Brasil. Todos sabem que uma página de Aníbal Machado é sempre uma página definitiva. Não faltaram, portanto, os mais imprevistos prognósticos quanto à maneira de como iria ele sair-se da empresa. Mas, ao entregar a sua parte, as atenções se transformaram em aplausos irrestritos. Superando-se a si mesmo, manteve "Brandão entre o Mar e o Amor" no mesmo elevado nível, entregando-o a Raquel de Queiroz, para que a romancista de "O Quinze" o concluísse.
\end{abstract}

(DIRETRIZES..., 1942, p. 21.)

É possível entrever no fragmento uma recepção crítica, e talvez refratária, dos leitores em relação à aparição do nome de Aníbal Machado na composição dos autores da obra. A qualidade literária do escritor, no entanto, agradou a ponto de a revista revelar ao final a apreensão causada. A aparição espaçada e futura dos seus livros confirmaria a aposta feita pela revista e confiança depositada pelos demais autores.

Se por um lado são cinco grandes escritores da literatura brasileira, por outro lado são escritores de cinco estados diferentes do Brasil. Uma questão que talvez se torne significativa, quando se tem em vista a construção de uma obra coletiva com autores de origens diferentes, está relacionada à escolha do espaço ficcional. Jorge Amado, que inaugura o livro, parece tomar cuidado nesse sentido ao trazer um espaço universal amplo: de um lado uma fazenda, de outro o mar. José Lins do Rego, como mostramos, talvez pelo universo do autor que o antecedeu, delimita geograficamente o espaço no estado da Bahia, com destaque para a cidade de Salvador, ainda que não desenvolva. O espaço urbano só ganhará 
um relevo interessante na última parte, escrita por Raquel de Queiroz. É curioso pensar que justamente o escritor baiano acaba não abordando a cidade de Salvador pela ordem em que o livro se realizou e pela forma livre como se constituiu.

Com relação ao tempo, como comentamos, Jorge Amado fornece pontualmente a época, informando que a guerra parece inevitável, talvez cumprindo assim uma das poucas propostas para a obra. As notícias da guerra chegarão à fazenda e a Brandão por meio do rádio e ele seguirá para o mar, para estar não mais entre o mar e o amor, mas junto às águas e à guerra. Se a ideia é bem trabalhada por Aníbal Machado, como de fato é, a presença do caricatural e engraçado Dr. Jax traz complicação para a severidade das doenças que acometem os personagens. A partir do humor e existência do Dr. Jax, todo mal severo poderá ser passível de cura, ainda que isso não aconteça exatamente. Mas a possibilidade, por si só, já compromete um pouco a veracidade do mal de Brandão e de Mário, interferindo no andamento do enredo. Por outro lado, ao contrapor e unir ciência e misticismo, o escritor trabalha de maneira interessante com a cultura popular, o que é um ganho em alguns momentos.

Uma experiência realizada por Aníbal Machado no início da década de 1920 serve como contraponto interessante ao livro Brandão entre o mar e o amor. Trata-se da novela coletiva $O$ capote do guarda, publicada no extinto jornal Estado de Minas de Belo Horizonte. Infelizmente esta obra hoje se preservou sem os cinco primeiros capítulos. A obra, também folhetinesca, possui uma forte preocupação com a ação, ainda que o enredo se complique em alguns pontos, e tem dimensão notadamente urbana. Como todos os escritores moram em Belo Horizonte, o espaço em comum aparece com grande coesão na obra e revela de maneira muito significativa a cidade da época e seu cotidiano. A perspectiva de mistério ligada a um roubo de um capote de um guarda civil une as partes de maneira consistente. A linguagem literária, no entanto, em algumas partes, poderia ser mais trabalhada, mas a obra surpreende nessa mesma questão numa visão maior. O capote do guarda fornece, nesse sentido, elementos para se pensar o romance Brandão entre o mar e o amor, como já pontuamos acima. Outra semelhança está no fato de Aníbal Machado também ter recorrido a um fato 
histórico, no caso a gripe espanhola, para redigir uma de suas narrativas. A solução é boa tanto naquele caso quanto neste.

A inspeção de uma parte como a escrita por Graciliano Ramos pode ser reveladora para uma avaliação da obra em questão. Quando observamos, na narrativa, o tratamento coisificado que é dado ao personagem Mário, que, como um móvel inútil, sente ser espanado. A ideia de espanar se mistura inicialmente na mente confusa de Mário com o curativo que lhe faz a personagem Lúcia para em seguida, com pedaços de algodão, cortar-lhe as carnes. Graciliano funde a violência do corte com a suavidade da carícia da mão feminina. Num movimento transitório, acompanhamos as divagações e lembranças que acometem o personagem enfermo. Com isso, fragmentos de vida vão surgindo: uma orientação do pai desaparecido; a ausência do amor e a mulher que não lhe escreve mais; a aparição de Glória, sua esposa, que lhe é pouco significativa; as frases que anota num caderno... Temos assim, uma narrativa de grande qualidade, assinada por um grande escritor. Quando avaliamos Brandão entre o mar e o amor como um todo, o romance não possui a mesma força que as partes, quando vistas de perto. Talvez sobreviva hoje mais pela força que os nomes dos grandes autores atribuem a ela, do que por sua própria construção como obra literária. Sobrevive como uma curiosidade literária, que parece servir mais à crítica literária do que ao leitor comum, ainda que este encontre motivos para lêla tanto numa perspectiva intrínseca, ainda que merecedora de reparos, quanto numa perspectiva extrínseca e plural.

\section{Referências}

AMADO, Jorge et al. Brandão entre o mar e o amor. São Paulo: Livraria Martins, 1942.

DIRETRIZES: POLÍTICA. ECONOMIA. CULTURA. Rio de Janeiro, 1938-1946. Disponível em: <https://bndigital.bn.gov.br/artigos/diretrizes/>. Acesso em: 21 jun. 2018. A revista foi dirigida Azevedo Amaral, Samuel Wainer e, posteriormente, também por Maurício Goulart. 
MORAES, Dênis de. O velho Graça: uma biografia de Graciliano Ramos. São Paulo: Boitempo, 2012.

PALAMARTCHUK, Ana Paula. Entre o mar e o amor... guerra e romance no Brasil contemporâneo. Cadernos do Tempo Presente, São Cristóvão, n. 4, n. p., 4 jul. 2011. Disponível

em: <https://seer.ufs.br/index.php/tempo/article/view/2718/2372>. Acesso em: 30 maio 2018. ISSN 2179-2143.

RAMOS, Graciliano. S. Bernardo. 83. ed. Rio de Janeiro: Record, 2006.

REVISTA DA ACADEMIA MINEIRA DE LETRAS. Belo Horizonte: AML, ano 83, v. 38, out./dez. 2005. Trimestral. Publicação parcial de $\mathrm{O}$ capote do guarda contendo textos de Carlos Góis, Ernesto Cerqueira e Laércio Prazeres.

- Belo Horizonte: AML, ano 84, v. 39, jan./mar. 2006a. Trimestral. Publicação parcial de $\mathrm{O}$ capote do guarda contendo textos de Berenice Martins Prates e João Lúcio.

. Belo Horizonte: AML, ano 84, v. 40, abr./jun. 2006b. Trimestral. Publicação parcial de $\mathrm{O}$ capote do guarda contendo textos de Aníbal Machado, Carlos Góis, Ernesto Cerqueira e Laércio Prazeres.

Belo Horizonte: AML, ano 84, v. 41, jul./set. 2006c. Trimestral. Publicação parcial de $\mathrm{O}$ capote do guarda contendo textos de Milton Campos, João Lúcio, Aníbal Machado e Carlos Góis.

\footnotetext{
* Doutor em Literatura Brasileira pela Universidade de São Paulo e professor do curso de Letras e do mestrado acadêmico de Letras da Universidade Estadual de Mato Grosso do Sul.
} 